\title{
V. On a remarkable heat observed in masses of brine kept for some time in large reservoirs
}

\section{G.A. Prinsep Esq.}

To cite this article: G.A. Prinsep Esq. (1839) V. On a remarkable heat observed in masses of brine kept for some time in large reservoirs, Philosophical Magazine Series 3, 14:85, 26-32, DOI: $10.1080 / 14786443908649653$

To link to this article: http://dx.doi.org/10.1080/14786443908649653

册 Published online: 01 Jun 2009.

Submit your article to this journal $[\pi$

Џ Article views: 2

Q View related articles $\square$ 


\section{$26 \mathrm{Mr}$. G. A. Prinsep on the spontaneous heating of Brine}

whole of the preceding observations. I have put them together for the purpose of suggesting to other inquirers certain sources of agency which it would appear must be necessarily followed by certain effects. That these should become sensible in themselves is what one should naturally expect; but if it should prove otherwise, it is worth while to inguire how it happens that they are lost. Whether, or how, they can be further traced I cannot now inquire; but it seems reasonable to suppose that considerations involving time and space to the amount of two seconds, and 400,000 miles, ought not to be neglected as indifferent to investigations, where appreciable phænomena supply measurements, in the case of a wave of light, to the ten millionth part of an inch, and the quadrillionth of a second.

I remain, Gentlemen, yours, \&c.

November, 1838.

J. S. W.

V. On a remarkable Heat observed in Masses of Brine kept for some time in large Reservoirs. By G. A. Prinsep, Esq. *

I the course of my experiments of several years in the manufacture of salt at Balya Ghát, on the salt-water lake east of Calcutta, I have sometimes observed a high degree of temperature at the bottom of the brine reservoirs after they had been filled for some weeks with brine of less than one fourth saturation. But as the greatest heat observed did not exceed $104^{\circ}$ Fahr. which was under the maximum heat of the brine on the terraces, whence the reservoirs had been filled, I supposed the high temperature to be merely that of a warm stream of water let in at the hottest part of the day in May or June, and remaining below and unmixed with the cooler surface water, of less specific gravity, afterwards admitted. This opinion was strengthened by the gradual reduction of the temperature below to nearly that of the surface, before the end of the rainy season. I have frequently bathed in one of the reservoirs (about 550 feet long, 35 feet wide at top and 7 or 8 feet deep), in September and October, and have found the temperature of the water then pretty equal throughout. But on plunging into the same reservoir on the 17th September last, I was surprised to find the temperature near the bottom so warm as to be intolerable to the feet. Still however I imagined that the heat was only that which the sun had imparted to the terrace brine in the very sultry weather of June last, (1837) when I bad $120^{\circ}$ registered (4th June, $4 \mathrm{p}$. m.) for

- From the Journal of the Royal Asiatic Society of Bengal, vol. vii. p. 207. 
the brine of a terrace yielding salt: and believing the hottest water to be therefore near the bottom I tried the temperature there about a month afterwards by immersing an empty bottle at the end of a bamboo, fixing the mouth so that it would be filled about a foot from the ground. The contents when poured out were at the temperature of $120^{\circ}$. A similar experiment made on the same day in a circular brine reservoir at Narainpore (120 feet diam. and about 16 feet deep) gave $104^{\circ}$. But on a subsequent visit to Narainpore on the 29th October, I was startled to observe that a pump fixed against the wall of this reservoir, for the purpose of feeding the boilers, was actually bringing up water of the temperature of $130^{\circ}$ from a depth of about 12 feet. This very unexpected discovery determined me to contrive an instrument that should serve as a probe to ascertain both the temperature and the specific gravity or saltness of the water at different depths. Annexed is a drawing of the instrument employed: it consisted of a split bamboo with bamboo buckets fixed between at distances of one foot from centre to centre, the mouths of the buckets being corked, but the corks having small air-holes; and the mode of using the machine was, to let it down with the mouths of the buckets downwards, and then turn it round, after which the air bubbles indicated the progress of filling; and in ten minutes or a quarter of an hour, when these disappeared, the machine was quickly drawn up and the temperature of the water in the buckets was tried rapidly in succession with a small thermometer, leaving the specific gravity to be tried afterwards.

On the day of the first trial of this probe I was favoured with the company and assistance of Dr. Huffnagle, who took a lively interest in the experiment. The following particulars are the results of all the trials $I$ have yet made with it, the buckets being numbered from the bottom of the machine.

First Experiment, 5th November, 9 А.м.

Open long reservoir at Balya Ghát. Probe immersed at an angle of $45^{\circ}$ or $50^{\circ}$.

\begin{tabular}{|c|c|c|c|c|c|c|}
\hline & & & & & & \\
\hline 1 & 106 & only & full. & & & \\
\hline 2 & 120 & S. G. & (appt.) & 1077 & at $T$. & 117 \\
\hline 3 & $120 \frac{1}{2}$ & 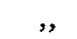 & 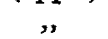 & $1073 \cdot 5$ & & \\
\hline 4 & $113^{2}$ & & & 1071 & & 110 \\
\hline 5 & 99 & & $\because$ & 1049 & ," & 97 \\
\hline 6 & 80 & & ", & 1022 & ", & 80 \\
\hline 7 & $78 \frac{1}{2}$ & 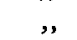 & , & 1022 & , & 78 \\
\hline 8 & $78^{2}$ &,$"$ & ," & 1021 &, & 78 \\
\hline 9 & 78 & ", & ", & $1023 \cdot 5$ &, & 78 \\
\hline
\end{tabular}


$28 \mathrm{Mr}$. G. A. Prinsep on the spontaneous heating of Brine

Second Experiment, 5 th November, 2 р.м. at Narainpore.

Open round brine reservoir. Probe at angle about $60^{\circ}$ south-west side.

\begin{tabular}{|c|c|c|c|c|c|c|}
\hline No. & Temp. & & & & & \\
\hline 1 & 105 & (appt.) & S. G. & $1163 a$ & T. & 100 \\
\hline 2 & 104 & not $f$ & cull, & & & \\
\hline 3 & 106 & (appt.) & S. G. & 1140 & ", & 104 \\
\hline 4 & 113 & ," &, & 1160 & ," & 108 \\
\hline 5 & 117 & ", & ," & 1161 & ", & 113 \\
\hline 6 & 123 & "? & ," & 1157 & ", & 117 \\
\hline 7 & 130 & ," &, & 1159 & , & 123 \\
\hline 8 & 132 & " & , & 1153.5 & , & 24 \\
\hline 9 & 137 & ," & , & 1145 & ", & 130 \\
\hline 10 & 131 & ," & ,, & $1: 21$ & ," & 125 \\
\hline 11 & 127 & , & , & 1100 & , & 120 \\
\hline 12 & 122 & ," & ," & 1090 & „, & 14 \\
\hline 13 & 114 & , & ," & 1075 & ," & 10 \\
\hline 14 & 104 & , & ," & 1065 & , & 101 \\
\hline 15 & 100 & ", & ", & 1065 & ", & 9 \\
\hline 16 & 85 & ", & .. & 1040 & ," & 0 \\
\hline 17 & 84 & ", & ", & $1044 \cdot 3$ & ", & \\
\hline 18 & 82 & & n & not full. & & \\
\hline 19 & 82 & ", & ", & 1038 & ," & \\
\hline
\end{tabular}

Third Experiment, 5 th November, $2 \frac{\mathrm{I}}{2}$ P.M. Same place and reservoir east side at gate. Probe at angle about $75^{\circ}$.

\begin{tabular}{|c|c|c|c|c|c|c|}
\hline to, & Temp. & & & & & \\
\hline i & 102 & (appt.) & S. G. & $1149 \mathrm{a}$ & $T$. & 100 \\
\hline 2 & 106 & ", & & $1145^{\circ} 3$ & ,, & 103 \\
\hline 3 & 109 & ", & not fu & & & \\
\hline 4 & 114 & ", & S. G. & 1175 & , & 111 \\
\hline 5 & 119 & , & ", & 1165.5 & , & 116 \\
\hline 6 & 128 & " & , & 1159 & , & 124 \\
\hline 7 & 137 & ," & , & 1155 & , & 130 \\
\hline 8 & 133 & ," &, & 1139 & $"$, & 128 \\
\hline 9 & 135 &, & , & 1125 & , & 127 \\
\hline 10 & 127 & ," & , & 1097 & , & 120 \\
\hline 11 & 114 & , & , & 1075 & , & 109 \\
\hline 12 & 105 &, & , & 1068 & ," & 101 \\
\hline 13 & 92 & ," & "\# & 1050 & "1 & 90 \\
\hline 14 & 86 & ", & ", & 1040 & $"$ & 8 \\
\hline 15 & $82 \frac{1}{2}$ & ," & , & 1038 & ", & 8 \\
\hline 16 & $81 \frac{1}{2}$ & , & ", & $1037 \frac{1}{2}$ & ", & 8 \\
\hline
\end{tabular}

Fourth Experiment, 19th November, 2 p.M., at Narainpore.

Open round brine reservoir south-west side. Probe at angle $60^{\circ}$.

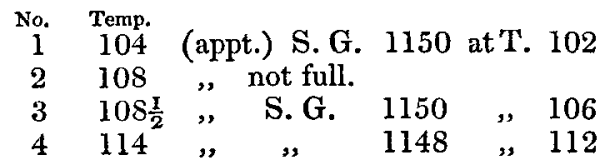


kept for some time in large Reservoirs.

\begin{tabular}{|c|c|c|c|c|c|c|}
\hline & Temp. & & & & & \\
\hline 5 & 125 & (appt.) & S.G. & $1166 \mathrm{a}$ & tr. & 120 \\
\hline 6 & 132 & ," & ", & 1151 & , & 124 \\
\hline 7 & 136 & ", & ," & 1142 & ", & 127 \\
\hline 8 & 133 & , & ", & 1126 & ", & \\
\hline 9 & 127 & " & ," & 109 & ," & \\
\hline 10 & 124 & ," & ," & 1070 & ", & 10 \\
\hline 11 & 117 & ", & ,, & 1061 & ", & 10 \\
\hline 15 & 99 & ", & ," & 1057 & ," & 9 \\
\hline 12 & 90 & ", & , & 1047 & ", & 90 \\
\hline 1 & 83 & ," & , & 1046 & $"$ & 8 \\
\hline 15 & $81 \frac{1}{2}$ & & ", & $1045 \cdot 6$ & ", & 8 \\
\hline 16 & $81^{2}$ & & , & 1045 & ", & 8 \\
\hline 17 & 82 & & ," & 1045 & , & 8 \\
\hline
\end{tabular}

Fifth Experiment, same date and place.

Covered reservoir. Probe at angle about $70^{\circ}$.

\begin{tabular}{|c|c|c|c|c|}
\hline No. & Temp. & & & \\
\hline 1 & 88 & (appt.) & S. G. & 1147 \\
\hline 2 & 88 & ", & ", & $1124 \cdot 5$ \\
\hline 3 & 90 & ," & $"$, & 1107 \\
\hline 4 & 91 & $"$ & ", & 1107 \\
\hline 5 & 90 & ", & ", & $1102 \cdot 6$ \\
\hline 6 & 90 & ," & ", & 1094 \\
\hline 7 & 89 & ", & " & 1081 \\
\hline 8 & 88 & , & ," & 1078 \\
\hline 9 & $87 \frac{1}{2}$ & ", & $"$, & 1069 \\
\hline 10 & - & empty. & & \\
\hline 11 & 82 & $"$ & $"$, & 1054 \\
\hline 12 & $80\}$ & \multirow{4}{*}{\multicolumn{2}{|c|}{ not full. }} & \\
\hline 13 & $77\}$ & & & \\
\hline 14 & 76 & & & 1046 \\
\hline 15 & 76 & & & 1046 \\
\hline
\end{tabular}

Sixth Experiment, same date and place.

Large reservoir. Probe at angle about $80^{\circ}$. Tried at $2 \frac{\mathrm{I}}{2}$ P.м.

\begin{tabular}{|c|c|c|c|c|}
\hline No. & Temp. & & & \\
\hline 1 & $93 \frac{1}{2}$ & (appt.) & S. G. & 1070 \\
\hline 2 & $93 \frac{\mathrm{I}}{2}$ & ", & $"$ & 1070 \\
\hline 3 & 93 & ", & ,", & 1069 \\
\hline 4 & 92 & ", & ," & 1067 \\
\hline 5 & $9 \mathrm{I} \frac{\mathrm{I}}{2}$ & "' & " & 1064 \\
\hline 6 & $90^{4}$ & ," & , & $1064 \cdot 5$ \\
\hline 7 & 87 & ," & ," & 1057 \\
\hline 8 & 85 & ," & , & 1056 \\
\hline 9 & 84 & :, & ," & 1050 \\
\hline 10 & 84 & , & , & $1050 \cdot 5$ \\
\hline & 84 & $(\operatorname{not} \mathrm{ft}$ & ll). & \\
\hline 12 & 84 & " & " & 1050 \\
\hline
\end{tabular}


$30 \mathrm{Mr}$. G. A. Prinsep on the spontaneous heating of Brine

Seventh Experiment, 3rd December, 2 р.м. at Narainpore.

Open round reservoir, tried in the centre, probe nearly perpendicular.

No. 1 'T. 107 half full.

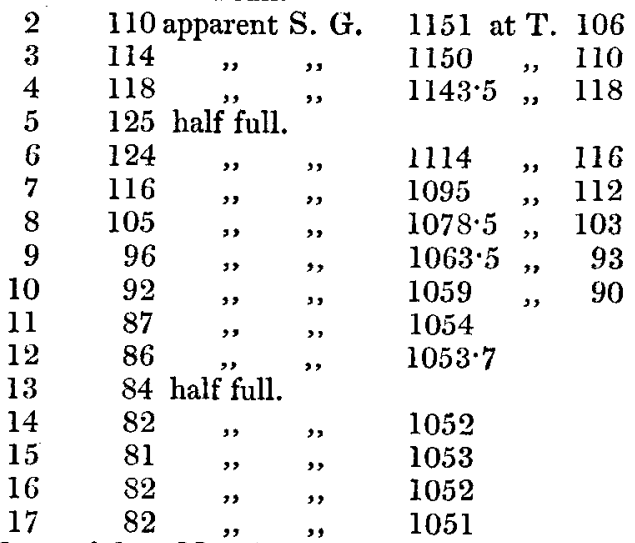

In the first trial at Narainpore the greatest heat was found about half-way from the bottom. The difference in that respect at Balya Ghát, where the greatest heat appeared at the second and third foot from the bottom, may be explained by the small depth of the reservoir at the latter place, the surface water being liable to be affected to the same depth in both by the wind and rain and temperature of the atmosphere; and the subsequent descent of the maximum heat at Narainpore is attributable in part to the expenditure of the brine there, being pumped out from near the bottom for the supply of the boilers. The highest temperature given by the probe at Narainpore was $137^{\circ}$, but this is $5^{\circ}$ less than the maximum given by the pumps, as will be seen by the following statement.

29 Oct. N.pump T. 130 S. G. (cor.) 1180

12 Nov. ," ," $138 \quad, \quad, 1170$

$19, \quad, \quad, \quad, 142 \quad, \quad, \quad 1162$

$26 \quad, \quad, \quad, \quad, \quad, 140 \frac{1}{2} \quad, \quad, \quad, 1152$

3 Dec. " , " $137 \quad, \quad, \quad 1133$ S. pump 134 S.G.1172

$10 \quad, \quad " \quad, \quad, 124 \quad, \quad$ " $1173 \quad, \quad 124,1158$

$17, ", \quad ", \quad, 125 \quad, \quad, \quad 1153 \quad, \quad 124 \quad, 1175$

24 " " , , $119 \quad, \quad$ " $1173 \quad, \quad 116,1171$

$31, ", \quad, \quad, 116 \quad, \quad, 1174 \quad, \quad 114 \quad, 1179$

7 Jan. " " " $102 \quad, \quad$ " $1133 \quad$ " $106 \quad, 1128$

13 "(sunk 2 feet) $104 \quad$ " $\quad$ " $1177 \quad$ " $100 \quad, 1132$

4 Feb. $\quad 90 \frac{1}{2}$ ", " 1100 " 92 , 1119

$10, \quad \ldots \ldots \ldots \ldots \ldots \ldots \ldots \ldots \ldots \ldots, \quad 90, " 1110$

As the temperature of $90^{\circ}$ was only about the mean of June, and also that of the lower moiety of the brine in the 
covered reservoir on the 19 th November, which was all nearly of an equable temperature, I consider the influence of the heating course to have ceased in the first week of February, if not before. The reservoirs have since been pumped dry, and therefore these experiments cannot be repeated, until they are replenished with brine in April or May next.

It is remarkable that the probe indicated no signs of a heating influence affecting the water in the large reservoir at Narainpore on the 19th November, though the specific gravity of the brine near the bottom was little less than that of the water in the long reservoir at Balya Ghát on the 5th November, its mean spec. grav. being also considerably higher than the mean of the latter. Moreover the heating influence was scarcely traceable in the covered brine reservoir at Narainpore on the 19th November, which perhaps may be accounted for by the large previous expenditure of brine, say about threefourths of its original contents, the consumption of which had been replaced to within a foot of the general level by filtration from the ground and leakage at the gate communicating with the adjoining terrace and brine fields; whereas the expenditure of brine in the contiguous open round reservoir otherwise similarly situated, was but half of the original contents up to the middle of January, its entire volume being about 170,000 cubic feet, while the covered reservoir contained only about 50,000. In these two reservoirs all the brine when first let in was of a high degree of saturation, ranging from 1170 to $1200 \mathrm{sp}$. gr. and consequently containing little or no sulphate of lime, which ingredient in the composition of seawater, I have observed at Balya Ghát, is always deposited upon the terraces there, considerably before the brine begins to deposit its sulphate of soda. But this was not the case with respect to the brine in the large reservoir at Narainpore, nor in that of a longer narrow one at Balya Ghát, except perhaps a small proportion of the latter, both of which were charged with brine of onlyl070 to $1085 \mathrm{sp}$. gr., a much higher degree however than that of the contents of the long reservoir in any previous year; and in both of them the water had remained undisturbed, except by the action of the atmosphere; yet in one of them a high degree of heat was observed, and in the other, where I should sooner have expected to find it, no indication of heat was perceived beyond the probable temperature at which it was filled in June.

In order to ascertain however whether any fermentation and disengagement of heat takes place on the mixture of saturated brine with brine of a weaker degree, I lately procured from Bulya Ghát some bottles of brine of different de- 
grees of saturation, with which the following experiments were tried.

1st Experiment.-Half a pint of saturated brine sp. gr. 1216, temperature 82.5 mixed with about the same quantity of brine of sp. gr. 1069, temperature $81 \cdot 2$. Result, temperature $82 \cdot 2$ and no effervescence after standing some minutes.

2nd Experiment.-Same quantities of brine sp. gr. 1216, temperature 82.5 , and of brine sp. gr. 1091 , temperature $81^{\circ}$. Result, sp. gr, $1152 \cdot 5$, temperature 82.2 and no effervescence.

3rd Experiment.-Same quantities of brine sp. gr. 1216, temperature $82 \cdot 5$, and $s p$. gr. 1135 , temperature $81^{\circ} 6$. Result, sp. gr. $1174 \cdot 3$, temperature $82 \cdot 1$ and no effervescence, nor any increase of temperature after remaining some hours in the glass.

Being therefore quite unable to offer any explanation of the cause of the remarkable heat observed in my brine reservoirs, I can only promise to register the temperature from time to time when they are filled again, in the hope that materials may thus be furnished to some scientific friend more capable of solving the interesting problem. If it should be discovered that a slow fermentation arising from the mixture of brine of different densities in large masses is the cause of this heat, it would seem to be accelerated by agitation, for the water raised by the pumps was always warmer than that which the probe brought up from the same depth; and, except at the first trial at Narainpore, always hotter than the maximum given by the probe.

VI. Notice of a Chemical Examination of a Specimen of Native Iron, from the East Bank of the Great Fish River, in South Africa. By Sir John F. W. Herschel, Bart., M.A., F.R.S.*

THE [portion analysed of the] specimen in question weighed originally $21 \cdot 79$ grains, $5 \cdot 12$ of which were separated, and submitted to a hasty preliminary examination for the detection of nickel, if any; but the quantity proving too small, the whole of the remainder was operated on in a subsequent trial.

The iron was highly malleable and tenacious, and apparently of excellent quality, with a somewhat whiter and more silvery lustre than belongs to the metal in its ordinary state,

* Read before the Literary and Scientific Institution of South Africa: now extracted from Sir James E. Alexander's " Expedition of Discovery into the Interior of Africa." Lond. 1838, vol. ii. Appendix, p. 272. The specimen had been found by Sir James Alexander, and presented by him to the Institution. 